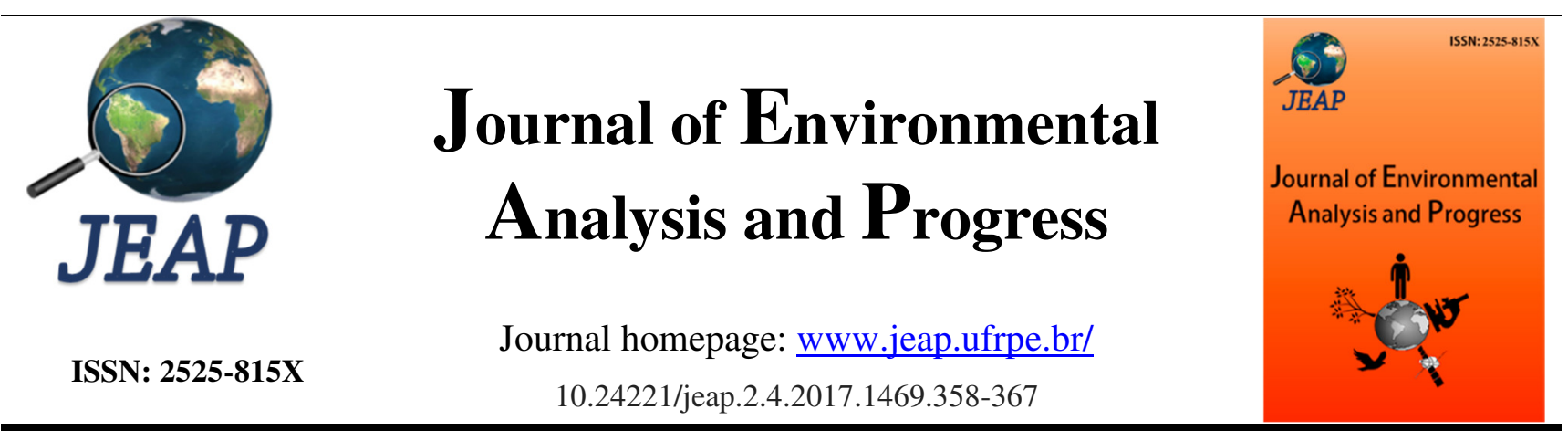

\title{
Índice de vegetação como subsídio na identificação de áreas com potenciais à desertificação
}

\section{Vegetation index as a subsidy in the identification of areas susceptible to desertification}

Joélia Natália Bezerra da Silva ${ }^{a}$, Jéssica Laís Bezerra da Silva ${ }^{b}$, Aldenice Correia da Silva ${ }^{a}$, Antonio Marcos dos Santos ${ }^{\mathrm{c}}$, Josiclêda Domiciano Galvíncio ${ }^{\mathrm{a}}$

a Universidade Federal de Pernambuco-UFPE, Av. Prof. Moraes Rego, n. 1235, Cidade Universitária, Recife, Pernambuco. CEP: 50670-901. E-mail: joelia.nataliageo@gmail.com; aldenicecs@ gmail.com; josicleda@gmail.com.

b Universidade Federal do Vale do São Francisco-UNIVASF, Rod. BR 407, Km 12, Lote 543, Projeto de Irrigação Senador Nilo Coelho, s/n, C1, Petrolina-PE, Brasil. CEP: 56.300-990, E-mail: jessica.laisb@ hotmail.com.

c Universidade de Pernambuco-UPE, Campus Petrolina, Rodovia BR 203, Km 2, s/n, Vila Eduardo, Petrolina-PE, Brasil. CEP: 56328-903. E-mail: geo_fisica@yahoo.com.br.

\begin{abstract}
A R T I C L E I N F O
Recebido 02 Jul 2017

Aceito 04 Ago 2017

Publicado 15

Ago 2017

A B S T R A C T

Desertification is an environmental problem that affects hundreds of hectares of land located in the dry regions of various parts of the planet. Several mechanisms are employed, among them remote sensing, to identify areas in the process of desertification. The study aimed to identify potential areas for desertification in the municipalities of Santa Maria da Boa Vista and Lagoa Grande, Pernambuco through Soil Adjusted Vegetation Index (SAVI). Two images obtained by the satellites Landsat 5 and Landsat 8 referring to the years 2005 and 2015 were used. Two municipalities showed areas with different potential for desertification, especially those related to the sparse caatinga and the regions with exposed soil. Some areas oscillated between fall and vegetation increase between 2015 and this due to the sensitivity of the index to pluviometric events that modified the vegetation cover structure. SAVI proved to be useful to identify areas with different desertification potentials but should be employed with another mapping method, since rainfall reflections on vegetation may compromise the Identification of risk areas.
\end{abstract}

Keywords: Caatinga, degradation, remote sensing.

R E S U M O
A desertificação é um problema ambiental que afeta centenas de hectares de terras
localizadas nas regiões secas de várias partes do planeta. Para identificação das
áreas em processo de desertificação vários mecanismos vêm sendo empregados,
entre eles o sensoriamento remoto. O objetivo deste estudo é identificar áreas com
potenciais à desertificação nos municípios de Santa Maria da Boa Vista e Lagoa
Grande, Pernambuco, através do Soil Ajusted Vegetation Index (SAVI). Duas
imagens foram obtidas pelos satélites Landsat 5 e Landsat 8, referentes aos anos de
2005 e 2015, respectivamente. Os resultados indicam que os dois municípios
apresentam áreas com diferentes potenciais à desertificação, principalmente,
aquelas relacionadas à caatinga esparsa e às regiões com solo exposto. Algumas
áreas oscilaram entre queda e aumento da vegetação entre 2015 e isto devido à
sensibilidade do índice aos eventos pluviométricos que modificaram a estrutura da
cobertura vegetal. O SAVI se mostrou eficiente na identificação das áreas com
diferentes potencias para desertificação, porém, deve ser empregado com outro


método de mapeamento, visto que os reflexos das chuvas na vegetação podem comprometer o processo de identificação das áreas de risco.

Palavras-Chave: Caatinga, degradação, sensoriamento remoto.

\section{Introdução}

Segundo a convenção de nações unidas de combate à desertificação (UNCCD), desertificação conceitua-se como a degradação das terras em áreas áridas, semiáridas e subúmidas secas, sendo o resultado de vários fatores como climático e ações antrópicas, podendo ser elas o mal-uso dos recursos naturais, como solo, sistema hídricos, vegetais, entre outros (United, 1994).

Três fatores podem são apontados como responsáveis pela degradação das terras susceptíveis a desertificação: remoção da camada fértil dos solos; redução do teor de água dos solos e acumulo de sais acima do tolerável para produção agrícola e manutenção da biodiversidade vegetal (D’Odorico et al., 2013).

Para compreender melhor os processos de degradação das terras que ocasionam na desertificação fazem-se necessário estudar o leque geral de suas causas, porém, também, não são descartados os estudos que envolvem apenas uma variável de degradação das terras incluindo aí o processo de uso e ocupação das terras. Neste contexto, o uso do sensoriamento torna-se de fundamental importância.

Novo (2010) define sensoriamento remoto como a utilização conjunta de sensores, onde são acoplados equipamentos para o processamento e transmissão de dados em aeronaves, espaçonaves e outras plataformas, tendo por objetivo estudar a eventualidades e processos que ocorrem na superfície terrestre a partir de registros e da análise das interações entre radiação eletromagnética e os objetivos de estudo com as suas diversas manifestações.

Segundo Vilhena, Tavares Júnior \& Beserra Neta (2012), o sensoriamento remoto vem sendo uma ferramenta que tem auxiliado os estudos geográficos, e que está sendo muito bem utilizado e valorizado pelos cientistas que tange principalmente ás questões ambientais e espaciais. Entre os produtos do sensoriamento remoto têmse os índices de vegetação.

Os índices de vegetação são intervenções matemáticas que são utilizadas para avaliar, monitorar e analisar a cobertura vegetal das possíveis mudanças que pode ocorrer na vegetação (Marcussis et al., 2010). Entre os índices de vegetação encontra-se o Soil Adjusted Vegetation Index (SAVI) que é considerado uma adaptação do NDVI, visto que, ele retira o brilho dos solos da interferência dos padrões da vegetação (Rosedo, 2005; Regô et al., 2012).
Este índice deve ser sempre adotado quando se pensa em monitorar ou avaliar coberturas vegetais com reduzida densidade (García \& Perez, 2016).

Diante do apresentado, o presente estudo tem como objetivo identificar as áreas com potenciais à desertificação nos municípios de Lagoa Grande e Santa Maria da Boa Vista a partir do SAVI.

\section{Material e Métodos}

A área de estudo corresponde a dois municípios da Microrregião de Petrolina, Lagoa Grande e Santa Maria da Boa Vista, ambos localizados no Estado de Pernambuco (Figura 1).

O clima da região é classificado como semiárido pela classificação de Köppen que se enquadra como BSWH. As chuvas são concentradas entre os meses de novembro a abril com média anual de $578 \mathrm{~mm}$, temperatura média do ar de $26,5^{\circ} \mathrm{C}$, evaporação anual de $2.600 \mathrm{~mm}$ e umidade relativa média anual não superior a $50 \%$ (Beltrão et al., 2006).

A vegetação é basicamente composta pela caatinga hiperxerófila com trechos de floresta caducifólia, onde predomina a caatinga arbustivaarbórea, entremeada a trechos de caatinga arbustiva. Os municípios de Santa Maria da Boa Vista e Lagoa Grande apresentam a mesma fitofisionomia, observando-se uma vegetação típica de caatinga com fisionomia predominantemente arbustiva com elementos arbóreos, podendo ser densa ou aberta, com um estrato arbustivo (CODEVASF, 2007).

Predominam os solos com baixo desenvolvimento como os Neossolos (Quartizarênicos; Litólicos; Flúvicos e Regolíticos), além dos Planossolos e pequenas manchas de solos desenvolvidos como os Latossolos e Argissolos, entre outros (Castro \& Santos, 2015).

Os municípios de Santa Maria da Boa Vista e Lagoa Grande estão inseridos na unidade geoambiental da depressão sertaneja, que representa a paisagem típica do semiárido nordestino. O relevo predominante é o suaveondulado com superfície de pediplanação em vales estreitos e vertentes dissecadas. As elevações de cristas ou outeiros testemunham a intensa erosão que atingiu está porção (Beltão et al., 2006). 

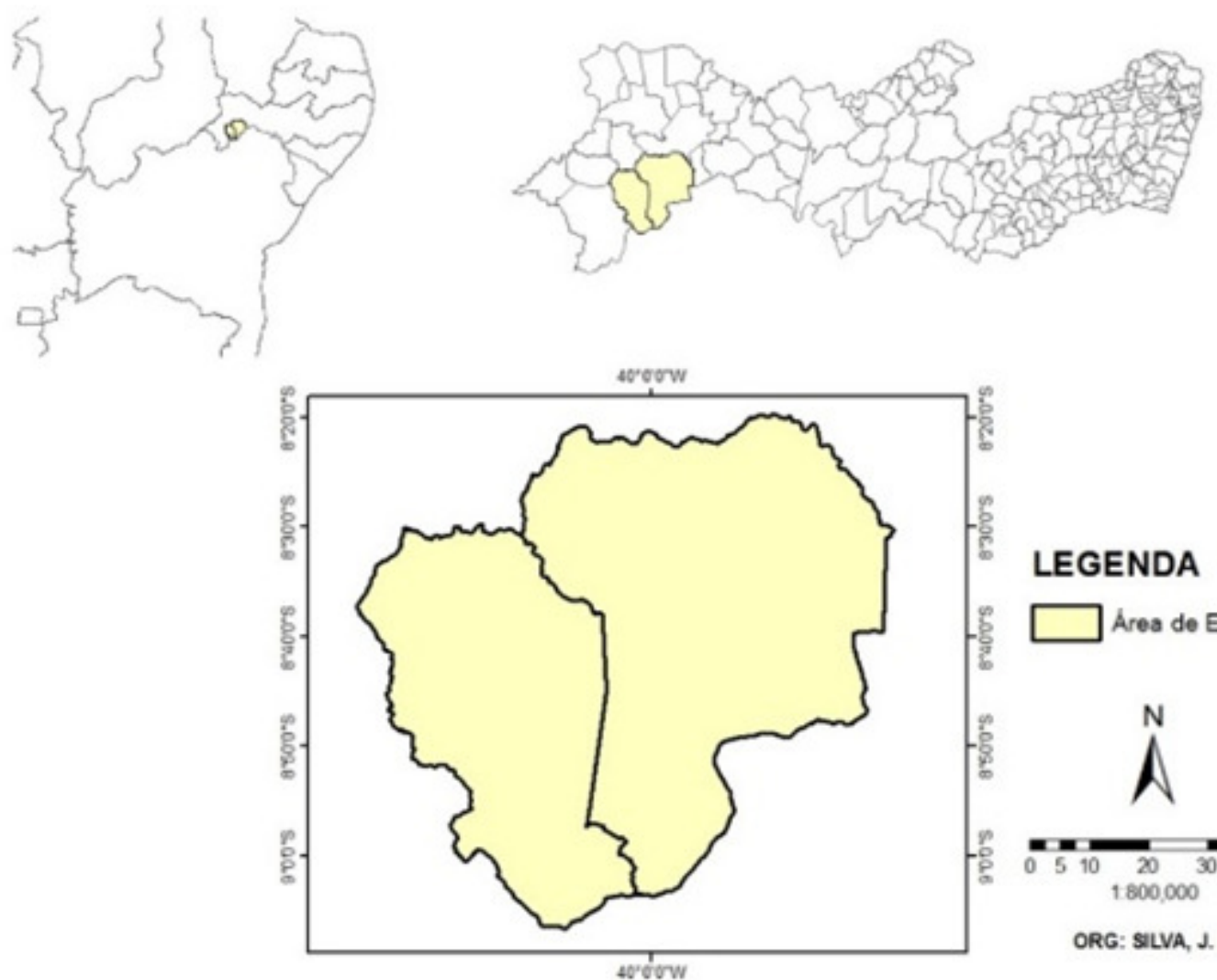

LEGENDA
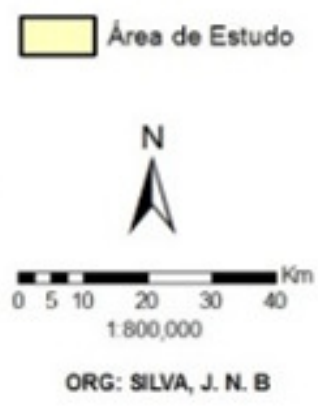

Figura 1. Localização dos municípios de estudo no estado de Pernambuco, Brasil. Fonte: Autores (2017).

Quanto aos aspectos populacionais, os dois munícipios possuem juntos 64.235 mil habitantes, sendo que a maior população se encontra concentrada no município de Santa Maria da Boa Vista com 39.435 habitantes, em seguida Lagoa Grande com 22.760 habitantes (IBGE, 2010).

O primeiro processo para elaboração deste estudo foi a aquisição de imagens orbitais no site do Instituto Nacional de Pesquisa Espacial (INPE), solicitadas no catalogo de imagens Landsat. Foram selecionadas duas imagens geradas pelo sensor Thematic Mapper (TM) e outra pelo sensor Operational Land Imager (OLI), acoplado ao satélite Landsat 5, uma do mês de junho de 2005 e outra do mês de abril de 2015, respectivamente. As imagens foram processadas através de softwares como o ERDAS 9.3 e ARCGIS 9.3 (ambos trabalhados sob a licença do Laboratório de Sensoriamento Remoto e Geoprocessamento-SERGEO do Departamento de Ciências Geográficas da Universidade Federal de Pernambuco).

De posse dos produtos orbitais, as mesmas foram submetidas ao registro (reposicionamento geográfico) com base em uma imagem gerada pelo mesmo sensor, porém, georreferenciada. Em seguida a imagem registrada foi submetida ao processo de calibração radiométrica, onde foram obtidas a radiância e a reflectância espectral conforme a Equação 1 e 2, respectivamente.

$$
L \lambda=a i+\left(\frac{b i+a i}{N D}\right) N D
$$

onde $a i$ e $b i$ são, respectivamente, as radiâncias espectrais mínimas e máximas. $N D$ é a intensidade do pixel, e 225 é o número inteiro de 0 a 225 , sendo uma constante, e o i correspondem às bandas do sensor TM.

$$
\rho \lambda=\frac{\pi \cdot L_{\lambda}}{K \lambda i \cdot Z \cdot d r}
$$

onde $L \lambda i$ é a de cada banda, $k \lambda i$ é a irradiância solar espectral de cada banda no topo da atmosfera, $Z$ é o ângulo zenital solar e $d r$ é o quadrado da razão entre a distância média TerraSol e a distância Terra-Sol $(r)$ em determinado dia do ano.

Após a reflectância espectral foi obtido o SAVI, proposto por Huete (1988) e descrito na Equação 3. Este índice contribui na identificação e separação da cobertura vegetal em relação aos demais elementos presentes na área de estudo. Segundo Santos \& Galvíncio (2013), o SAVI é bem utilizado em áreas onde a vegetação é rarefeita, menos densa, isto porque, ao contrário 
dos demais índices de vegetação, este evita os efeitos da refletância dos solos sobre a cobertura vegetal não prejudicando o mapeamento.

$$
S A V I=\frac{(1+L)\left(\rho_{i v}-\rho_{v}\right)}{\left(L+\rho_{i v}+\rho_{v}\right)}
$$

onde Piv e $P v$ correspondem às bandas 4 (refletância no infravermelho próximo) e 3 (refletância na faixa espectral do vermelho) dos sensores acoplados no Landsat, respectivamente, e L é o fator da função do tipo de solo.

De acordo com Huete (1988 apud Ponzoni \& Shimabukuro, 2009) o fator de ajuste $L$ tem por objetivo ajustar a função dos diferentes biomas, considerando a densidade da vegetação, onde o fator $L=1$ é utilizado para baixas densidades da vegetação, $L=0,5$ para medias densidades e $L=0,25$ para altas densidades.

\section{Resultados}

A Figura 2 apresenta a carta do SAVI para o ano de 2015 e a Figura 3 o SAVI para o ano de 2015 refeente aos municipios de Lagoa Grande e Santa Maria da Bioa Vista. Foram estabelecidas três classes que podem ser relacionadas à presença ou ausência da cobertura vegetal, com maior ou menor intensidade. As áreas com SAVI variando entre 0 a 0,1 apresentam reduzida cobertura vegetal, culminando com áreas de solo exposto (Figura 3).

Neste contexto, quanto mais próximo de 0 menor a presença da vegetação. Encaixam-se nesta categoria as áreas com solo exposto, agricultura de sequeiro ou terrenos com plantações em fases iniciais e, a depender, da resolução espacial das imagens áreas com pastagens de pequena intensidade.
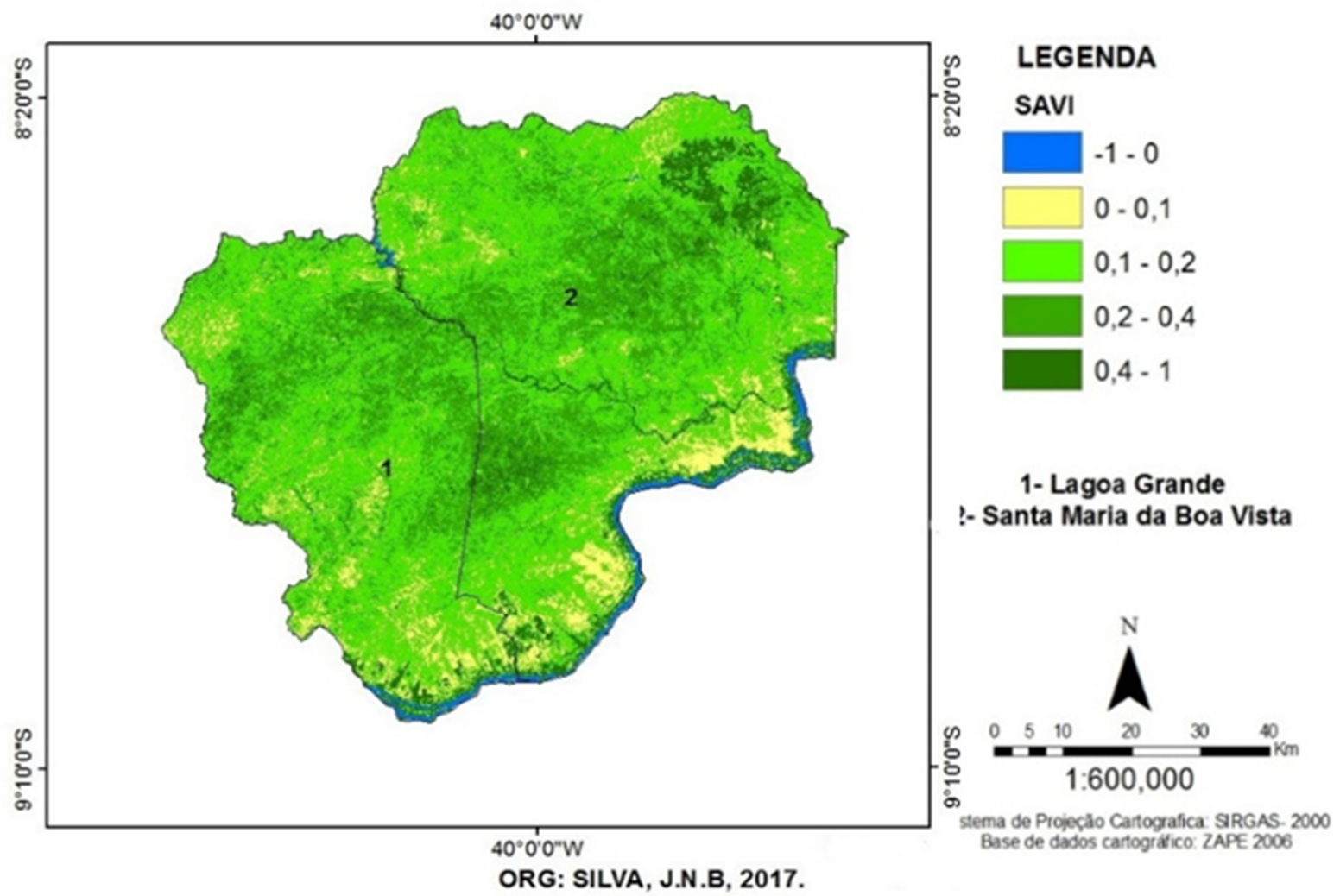
Base de dados cartográfico: ZAPE 2006

Figura 2. Cartas do Soil Adjusted Vegetation Index (SAVI) para os anos de 2005, em Lagoa Grande e Santa Maria da Boa Vista. Fonte: Autores (2016).

As áreas sobre solo exposto podem acarretar alguns problemas que contribuirão com o processo de desertificação. Um deles é a erosão dos solos. O solo desprotegido torna-se vulnerável aos impactos das gotas das chuvas, consequentemente, ocorrem perdas de materiais que culminam com a perda de fertilidade. 

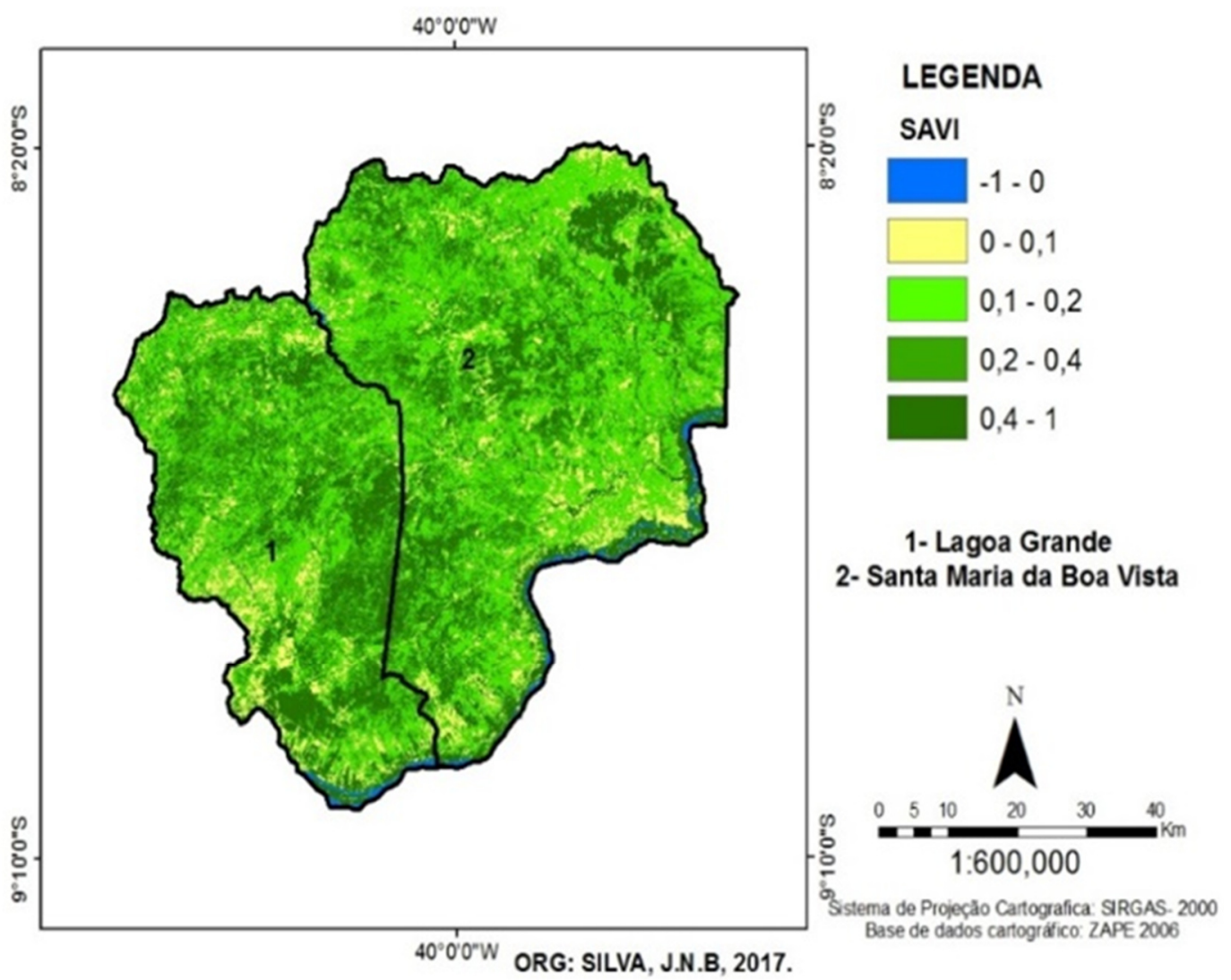

Figura 3. Cartas do Soil Adjusted Vegetation Index (SAVI) para os anos de 2015, em Lagoa Grande e Santa Maria da Boa Vista. Fonte: Autores (2016).

A Figura 4 apresenta uma área de solos em Santa Maria da Boa Vista no ano de 2016.
Nessas áreas os riscos de erosão são amplos, comparadas com as área sobre cobertura vegetal.

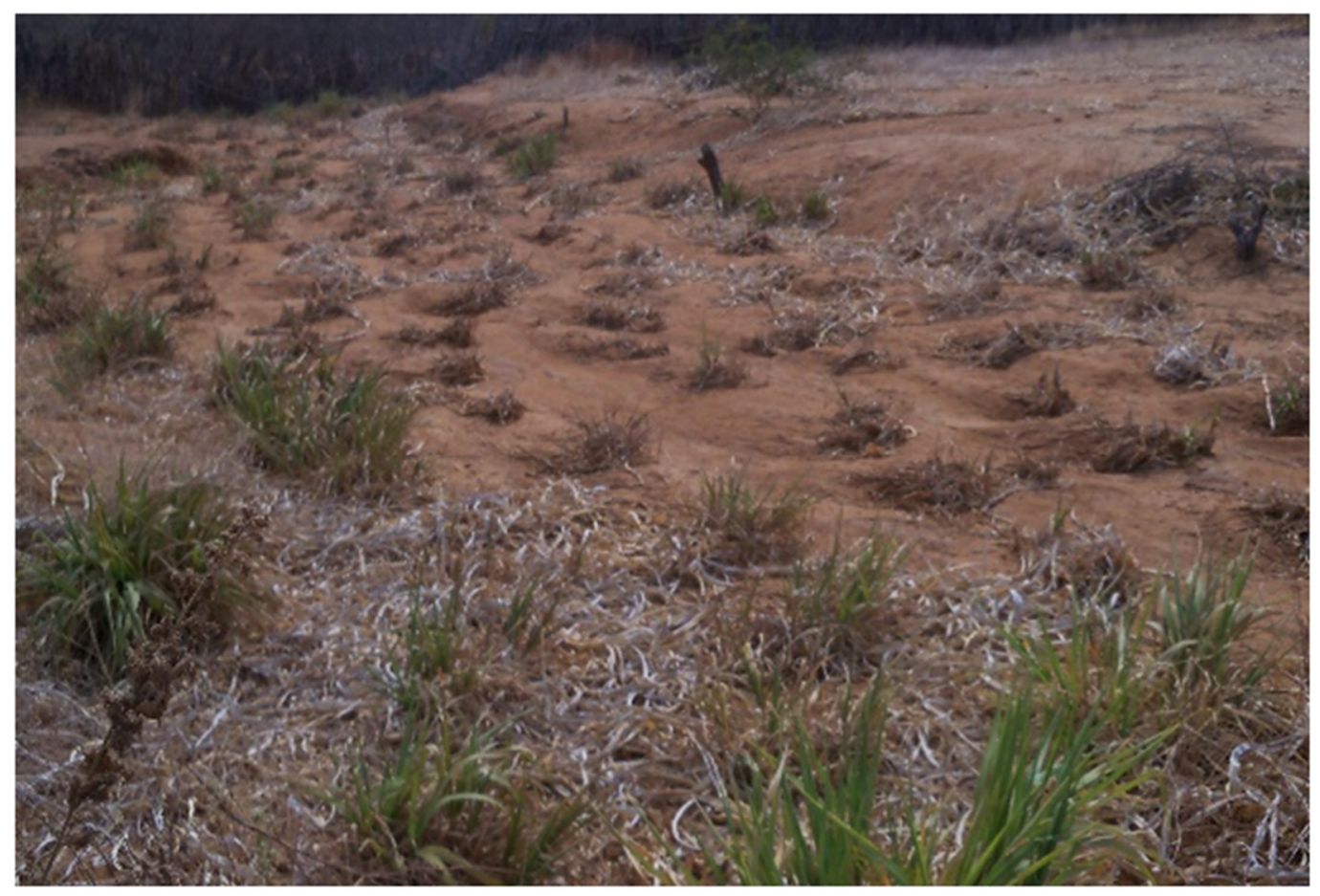

Figura 4. Área com solo exposto no município de Santa Maria da Boa Vista, em 2016. Fonte: Autores (2016). 
A Figura 5 apresenta uma área de solo município de Lagoa Grande. exposto sendo visível uma cicatriz erosiva no

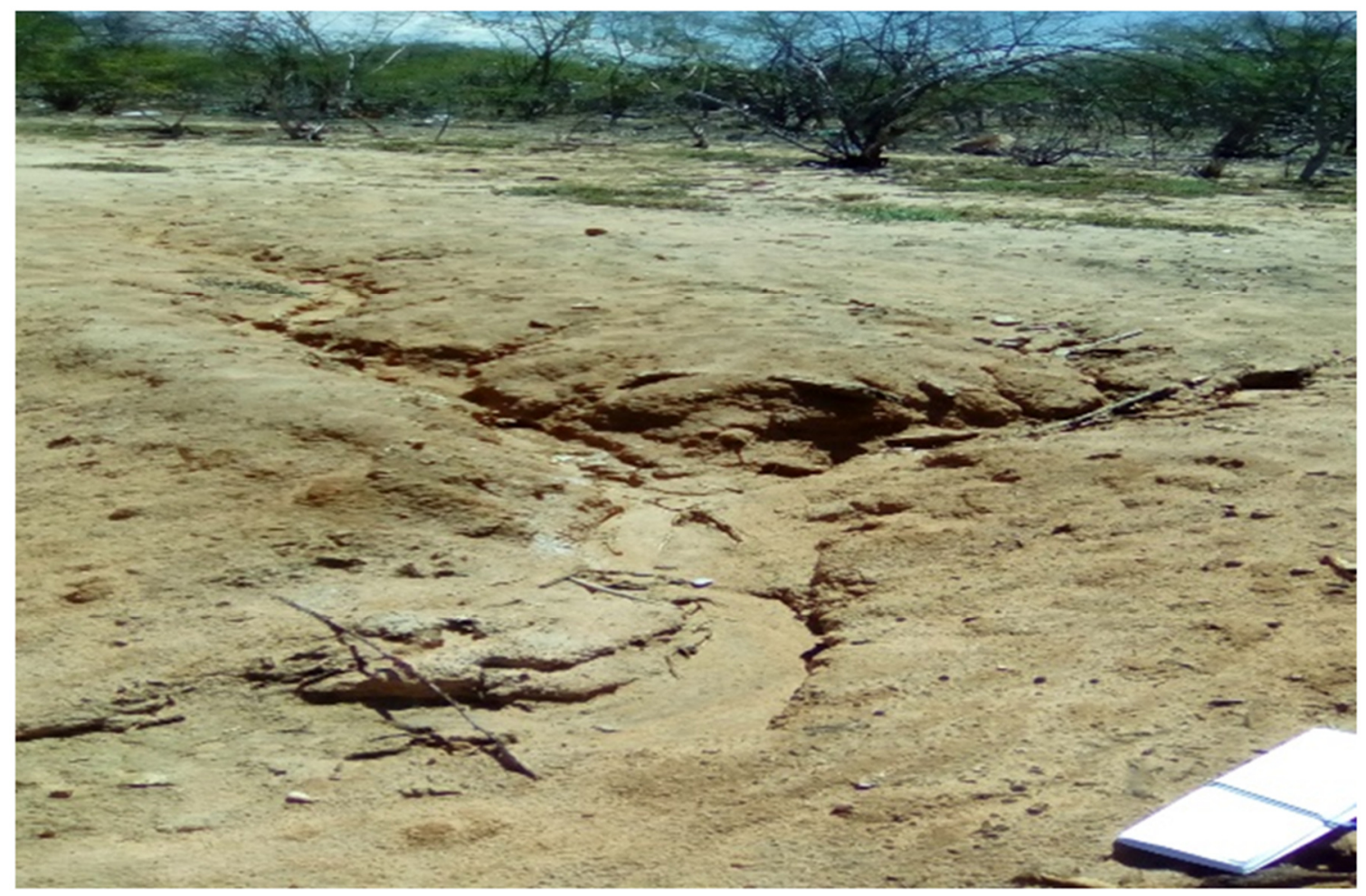

Figura 5. Cicatriz erosiva em área sem cobertura vegetal no município de Lagoa Grande, em 2016. Fonte: Autores (2016).

Estima-se que no ano de 2005 o solo exposto ocupava $13,2 \%$, no ano de 2015 alcançou
$12,4 \%$. Observa-se que houve redução das áreas com solo exposto (Figura 6).

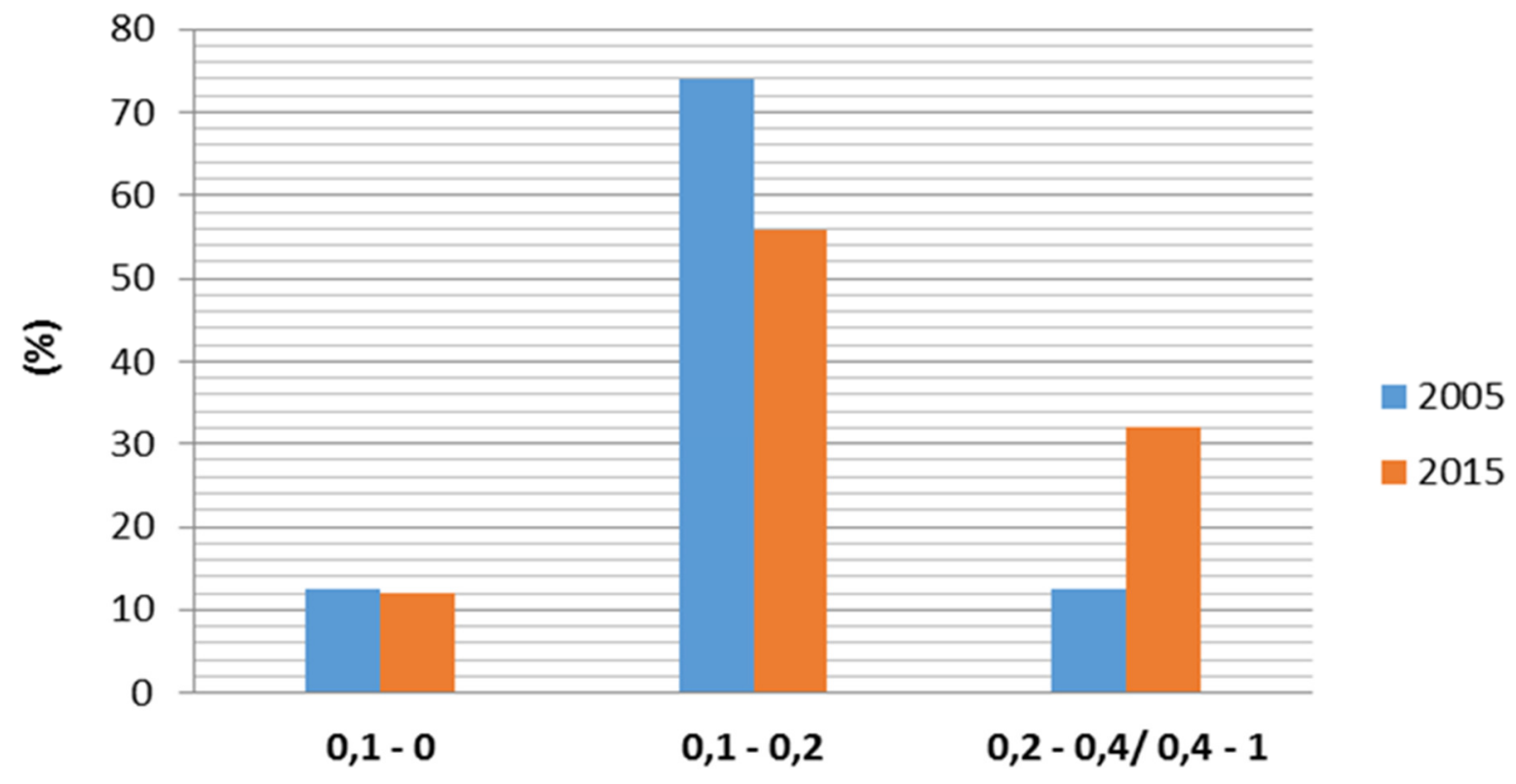

\section{Classe de IVAS}

Figura 6. Quantitativo de áreas para cada classe de Soil Adjusted Vegetation Index (SAVI) para os anos de 2005 e 2015. 
As áreas com SAVI entre 0,1 a 0,2 representam pouca densidade da vegetação ou cobertura vegetal mais baixa/esparsa muito próxima do solo exposto. No ano de 2005 a classe de SAVI entre 0,1 a 0,2 ocupava $73,8 \%$, enquanto que, no ano de 2015 o quantitativo de áreas ocupadas foi de $55,5 \%$. Observa-se que houve redução das áreas com solo exposto entre os 10 anos de análise (Figura 6). Pode-se notar que houve a predominância da classe caatingas esparsa.

A redução de área pontuada anteriormente foi de $18,3 \%$. Esta diminuição aconteceu devido a uma má distribuição das chuvas no território dos municípios analisados no ano de 2005. As chuvas foram concentradas em alguns locais em detrimentos de outros.

As áreas com caatinga esparsa estão associadas, em sua maioria, a espaços degradados.

A

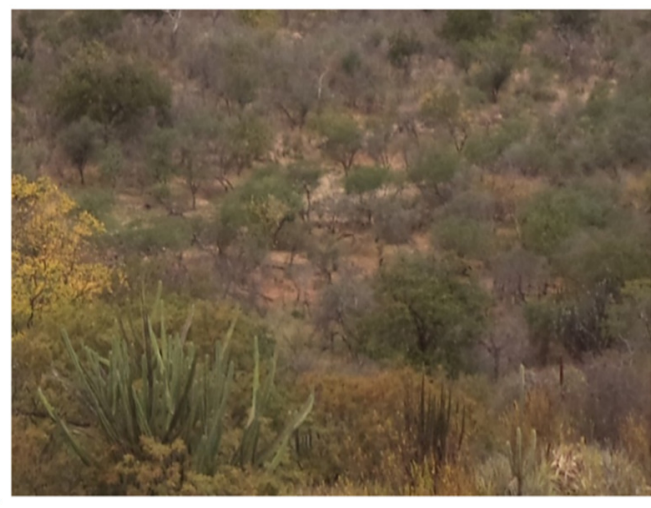

Em muitos dos casos são áreas destinadas às práticas relacionadas à criação de animais, como ovinos e caprinos, principalmente. Em outros casos, a espacialização da caatinga está associada à retirada de espécies paraa construção de cercas, produção de carvão vegetal e agricultura de sequeiro e irrigada.

A Figura 7 apresenta duas áreas de caatinga esparsa, em Lagoa Grande e em Santa Maria da Boa Vista, respectivamente, no ano de 2016. Observam-se clarões nos terrenos e o baixo porte arbóreo das espécies. Nestes locais, em comparação com as áreas sobre caatinga densa, o risco de erosão é maior e pode comprometer a manutenção da biodiversidade florística ao longo do tempo. Isto contribui para o avanço do processo de desertificação nestes locais.

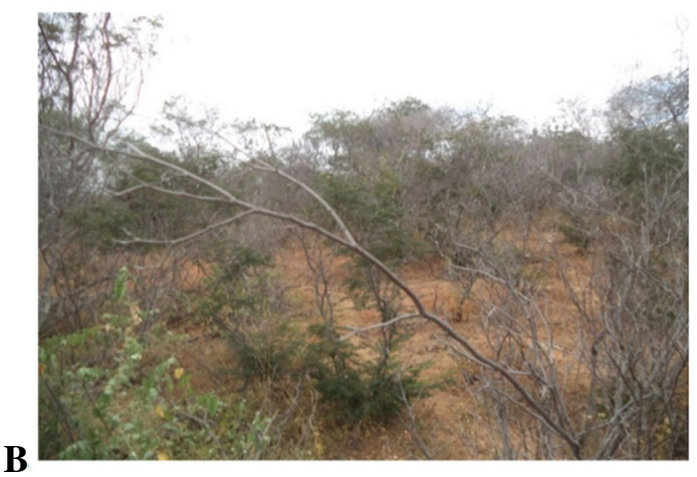

Figura 7. Áreas com vegetação de caatinga esparsa em: A. Lagoa Grande e B. em Santa Maria da Boa Vista, em 2016. Fonte: Autores (2016).

As classes de SAVI superior a 0,2 apontam para a presença da cobertura vegetal que varia entre a caatinga esparsa a densa. Inclui, também, as áreas sobre agricultura irrigada.

No primeiro ano de análise, 2005, 12\% entre os dois municípios apresentam SAVI entre 0,2 a 1 . No ano de 2015 este valor aumentou para $31 \%$.
No período do ano de 2015 observa-se maior predominância da caatinga densa (Figura 7). O aumento da classe pode ser explicado por dois fatores. O primeiro está relacionado à distribuição das chuvas que, apesar de totalizarem apenas $250 \mathrm{~mm}$ entre os meses de novembro de 2014 a abril de 2015 (Figura 9), foi distribuída de forma homogênea entre os dois municípios.

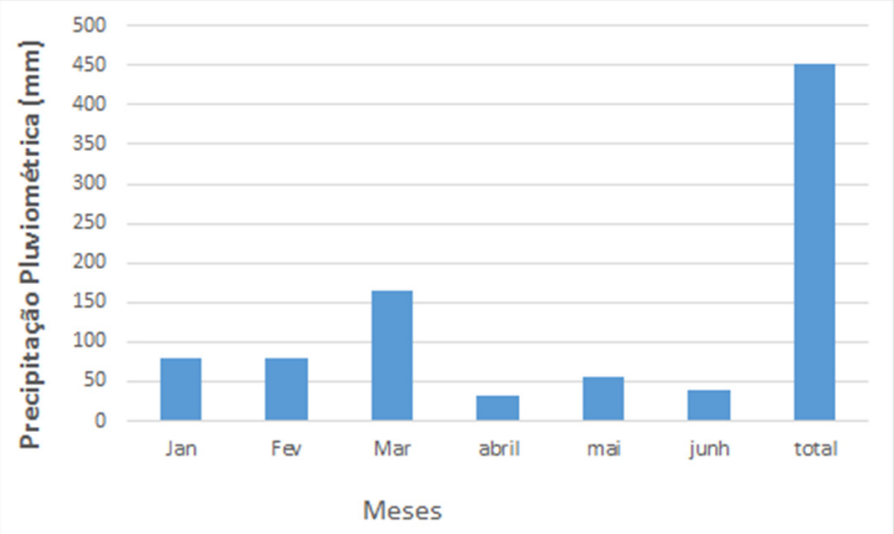

Figura 8. Precipitação pluviométrica referente aos seis primeiros meses do ano de 2005. Fonte: Estação Meteorológica de Bebedouro-Petrolina, EMBRAPA semiárido. 


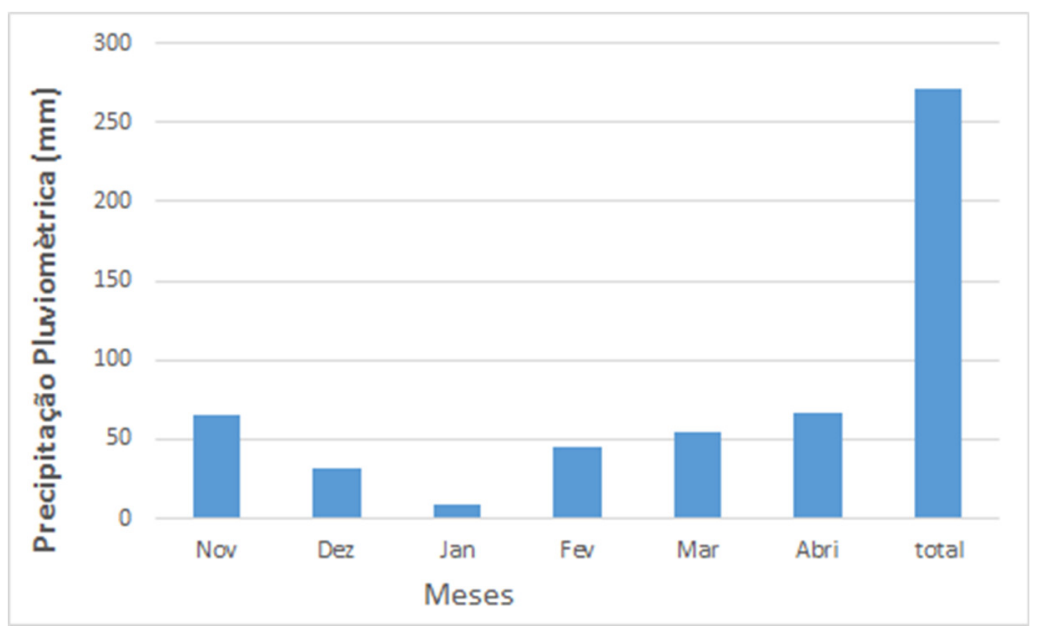

Figura 9. Precipitação pluviométrica referente aos meses de novembro e dezembro de 2014 e os quatro primeiros meses do ano de 2015. Fonte: Estação Meteorológica de Bebedouro-Petrolina, EMBRAPA semiárido.

\section{Discussão}

Boratto \& Gomide (2013) destacam que as áreas com solo exposto compreendem os valores de SAVI entre 0,3 a 0,55 , porém, neste intervalo é possível encontrar vegetação rala. Silva \& Cruz (2016) apontam que a classe 0 a 0,19 está atrelada presença do solo exposto.

Bezerra \& Cantalice (2006) relatam que a cobertura vegetal intercepta as gotas de chuvas, disipa energia cinética na queda e evita o seu impacto direto sobre a superfície.

De acordo com o Ministério do Meio Ambiente (2007), a diminuição na fertilidade do solo é um dos impactos mais recorrentes em áreas do semiárido nordestino oriundas das erosões acometidas pelos desmatamentos.

Um problema relacionado ao solo exposto é o aumento da temperatura de superfície. Soares et al. (2010), em estudo realizado no estado de Pernambuco, detectaram impactos relacionados ao desmatamento e aumento de temperatura de superfície dos solos. Destaque para o aumento da evaporação da umidade do solo e a migração de cupins dos solos para vegetação.

Segundo Figueiredo (2014), as classes de SAVI entre 0,48 a 0,71 apontam para presença de vegetação densa, no caso das caatingas indicam para uma estrutura de cobertura arbustiva fechada e arbórea densa.

No estudo de Silva \& Cruz (2016) atribuiu-se a classe de SAVI com valores acima de 0,5 para coberturas vegetais com alta atividade fotossintética, onde é possível identificar maior concentração de biomassa ativa.

Em estudo realizado por Silva \& Cruz (2016) o intervalo de valor do SAVI entre 0,19 a 0,2 foi atribuído à vegetação com baixa atividade fotossintética, estando associada à fisionomia da vegetação de estrato herbáceo e arbustiva aberta.
Outro fator a ser bastante considerado é o aumento da agricultura irrigada na região. Os índices com maior incidência do SAVI estão associados à biomassa verde (Silva \& Cruz 2016), que corresponde em maior frequência a áreas de fruticultura irrigada, sendo notado também em pequenas áreas de caatinga densa arbustiva.

A caatinga esparsa contribui para os riscos a erosão dos solos contribuindo para o avanço potencial da desertificação (Santos \& Galvíncio, 2013). O mesmo pode ser destacado para as áreas de solo exposto identificado sobre os municípios. Portando a região tem o risco moderado para áreas susceptíveis à desertificação.

\section{Conclusão}

A aplicação das técnicas de sensoriamento remoto no estudo da vegetação tem construído para obter bons resultados e auxiliar nas importantes ferramentas para o planejamento e acompanhamento de áreas susceptíveis à desertificação.

Nos municípios de Santa Maria da Boa Vista e Lagoa Grande, ambos no estado de Pernambuco, verificou-se que os índices utilizados no estudo corresponderam à análise da dinâmica da vegetação no que tange o acompanhamento de sua alteração espaçotemporal e sua relação com o índice pluviométrico.

O SAVI evidenciou a condição da vegetação entre os diversos períodos de precipitação, apresentando resultados satisfatórios quanto ao acompanhamento da dinâmica da vegetação ao longo dos anos de 2005 e 2015, nota-se a predominância da caatinga esparsa nos dois anos. Neste contexto, o SAVI mostrou-se eficiente na identificação das áreas com diferentes potencias a desertificação na área de estudo, 
porém, deve ser empregado com auxílio de outro método de mapeamento, visto que, os reflexos das chuvas na vegetação podem comprometer o processo de identificação das áreas de riscos.

\section{Agradecimentos}

À Fundação de Amparo a Tecnologia de Pernambuco (FACEPE) pela bolsa de Pósgraduação da primeira autora, ao Grupo em Pesquisa Sensoriamento Remoto e Geoprocessamento (SERGEO) pelo apoio à pesquisa, ao Grupo de Trabalho em Monitoramento Ambiental, Geotecnologia e Ensino (GTMAGEO) do Grupo de Pesquisa em Sociedade e Natureza no Vale do São Francisco (GPSNVSF) e à Universidade de Pernambuco (UPE) pelo apoio institucional.

\section{Referências}

BRASIL. 2007. Atlas das áreas susceptíveis à desertificação no Brasil. MMA, Brasília.

BELTRÃO, B. A.; MASCARENHAS, J. DE C.; MIRANDA, J. L. F.; SOUZA JUNIOR, L. C.; GALVÃO, M. J. DA T. G.; PEREIRA, S. N. 2006. Projeto cadastro de fontes de abastecimento por água subterrânea. Diagnóstico do município de Petrolina, estado de Pernambuco. CPRM/PRODEEM, Recife. 47p.

BEZERRA, S. A.; CANTALICE, J. R. B. 2006. Erosão entre sulcos em diferentes condições de cobertura do solo, sob cultivo da cana-de-açúcar. Revista Brasileira de Ciência do Solo, v. 30, n. 3, p. 565-573.

BORATTO, I. M. P.; GOMIDE, R. L. 2013. Aplicação dos índices de vegetação NDVI, SAVI e IAF na caracterização da cobertura vegetativa da região norte de Minas Gerais. Anais XVI Simpósio Brasileiro de Sensoriamento RemotoSBSR, Foz do Iguaçu-PR, Brasil, INPE. pp. 73457352.

CODEVASF. 2007. Brasil. Ministério da Integração Nacional-Estudo de Impacto Ambiental. Projeto Pontal Norte. Projetec. v. 1, estudos preliminares.

CASTRO, F. C.; SANTOS, A. M. 2015. Susceptibilidade ambiental a salinização das terras em municípios da microrregião de PetrolinaPernambuco-Brasil. Cam. Geo., v. 16, n. 56, p. 160-172.

GARCÍA, P.; PEREZ, E. 2016. Mapping of soil sealing by vegetation indexes and built-up index:
A case study in Madrid (Spain). Geoderma, v. 268, p. 100-107.

FIGUEIREDO, A. C. 2014. Dinâmica da vegetação e regime de precipitação em bacia hidrográfica da região semiárida de Pernambuco. Tese de Doutorado, Universidade Federal Rural de Pernambuco. Recife, Pernambuco. 167p.

HUETE, A. R. 1988. Adjusting vegetation indices for soil influences. Int. Agro., v. 4, n. 5, p. 367376.

IBGE. Censo Demográfico 2010. Características Gerais da População. Resultados da Amostra. Disponível em: http://www.censo2010.ibge.gov.br/sinopse/index. php?dados $=8$. Acesso em: 02 de fevereiro de 2017.

MARCUSSI, A. B.; BUENO, C. R. P.; MIQUELONI, D. P.; ARRAES, C. L. 2010. Utilização de índices de vegetação para os sistemas de informação geográfica. Cam. Geo., v. 11, n. 35, p. 41-53.

NOVO, E. M. L. M. 2010. Sensoriamento Remoto: princípios e aplicações. Edgard Blucher, São Paulo.

D'ODORICO, P.; BHATTACHAN, A.; DAVIS, K. F.; RAVI, S.; RUNYA, C. W. 2013. Global Desertification: Drivers and Feedbacks. Adv. Wat. Res., v. 51, p. 326-344.

PONZONI, F. J.; SHIMABUKURO, Y. E. 2009. Sensoriamento Remoto no Estudo da Vegetação. Parêntese, São José dos Campos.

REGÔ, S. C. A.; LIMA, P. P. S.; LIMA, M. N. S. 2012. Análise comparativa dos índices de vegetação NDVI e SAVI no município de São Domingos do Cariri- PB. Ver. GEO., ed. Especial, v. 2 , n. 4 p. $1217-1229$.

ROSENDO, J. S. 2005. Índices de vegetação e monitoramento do uso do solo e cobertura vegetal na bacia do rio Araguari- MG- utilizando dados do sensor Modis. Dissertação de Mestrado, Universidade Federal de Uberlândia. 130p.

SANTOS, A. M.; GALVÍNCIO, J. D. 2013. Mudanças Climáticas e Cenários de Susceptibilidade Ambiental à Desertificação em Municípios do Estado de Pernambuco. OBS., v. 5, n. 15 , p. 24-47. 
SILVA, F. C.; CRUZ, M. L. B. 2016. Analise da fisionomia da cobertura vegetal em ambientes semiáridos: caso do município de Jaguaretama, estado Ceará. Ver. Reg., v. 2, n. especial, p. 801809.

SILVA, F. H. B. B.; SILVA, M. S. L.; CAVALCANTI, A. C.; CUNHA, T. J. F. 2010. Principais solos do semiárido do nordeste do Brasil. Biblioteca digital da Embrapa, Recife. Disponível em: https://ainfo.cnptia.embrapa.br/digital/bitstream/C PATSA/34392/1/OPB1114.pdf. Acesso em: 04, abril, 2017.

SILVA, P. P. L.; MACHADO, C. C. C.; SILVA, B. S.; GALVÍNCIO, J. D. 2013. Análise espaçotemporal do IVAS e da temperatura da superfície no município de Serra Talhada-PE. XVI Simpósio Brasileiro de Sensoriamento Remoto-SBSR, Foz do Iguaçu-PR, Brasil, INPE. pp.6869-6876.

SOARES, D. B.; FILHO, F. O. M.; NOBREGA, R. S.; OLIVEIRA, T. H. 2010. Geoprocessamento e sensoriamento remoto como ferramentas de desertificação de áreas em processo de desertificação. In. GALVÍNCIO, J. D. (Orga.). Mudanças climáticas e impactos ambientais. EDUPE, Recife. pp. 35-56.

VILHENA, D. C.; TAVARES JÚNIOR, S. S. T.; BESERRA NETA, L. C. B. 2012. O sensoriamento remoto como recurso didático no ensino da geografia. Rev. GEON., ed. Especial, v. 2, p. 1624. 